\title{
A comparative study of various diagnostic techniques for Cryptosporidiosis
}

\author{
Nautiyal $\mathrm{S}^{1}$, Pinto $\mathrm{MJW}^{2}$, Rodrigues $\mathrm{S}^{2}$ \\ ${ }^{I}$ Shri Guru Ram Rai Institute of Medical and Health Sciences, Dehradun. \\ ${ }^{2}$ Goa Medical College, Bambolim Goa.
}

\begin{abstract}
Diarrhoeal disease is a common complication of infection with HIV. Cryptosporidium has gained importance as an AIDS indicator disease and a cause of intractable diarrhoea in immunosuppressed individuals. This warranted a study of stool specimens of HIV positive patients with $(n=60)$ and without $(n=60)$ diarrhoea along with their HIV negative counterparts $(n=200)$. Microscopic examination for ova and cysts were done using wet mount and Lugol's iodine preparation. Smears were stained with Kinyoun Cold Acid Fast $(K C A F)$ and Auramine 'O' fluorochrome (AOF) staining methods to identify Cryptosporidium oocysts. ELISA using Cryptosporidium microplate assay (alexon Inc) for detection of Cryptosporidium antigen was conducted on all stool specimens. By KCAF staining detection of Cryptosporidium in HIV positive subjects with diarrhoea was $20 \%$, by AOF it was $7.5 \%$ and by ELISA the detection rate went up to $30 \%$. All the detailed result were statistically compared taking KCAF staining as gold standard which revealed AOF staining to have sensitivity of $36.67 \%$ and specificity of $99.31 \%$ while ELISA was found to have sensitivity of $83.88 \%$ and specificity of $96.55 \%$. Keeping in mind the present scenario of HIV infection in India and more so in Goa, it is recommended to include detection of Cryptosporidium oocysts in routine parasitological examination of stool specimens and an urgent need to standardize a gold standard for various diagnostic tests presently available.

Key words: Auramine 'O' fluorochrome staining, Cryptosporidiosis, ELISA for Cryptosporidium antigen, Kinyoun Cold Acid Fast staining.
\end{abstract}

Submitted date 08 June 2013

Accepted Date: 15 June

\section{Introduction}

HIV infected persons like other immunosuppressed individuals, develop serious opportunistic infections. However, all organisms do not represent an equal threat [1]. Most of these patients die of infections other than HIV [2]. The gastrointestinal tract is the major surface where contact between man and environment takes place. At sometime during the clinical course of HIV, diarrhoea occurs in almost ninety percent of patients in developing countries [3] and is the presenting symptom of approximately a third of patients with HIV [4]. The number of HIV-positive patients is increasing in India, data on the prevalence of diarrhoea and the spectrum of pathogens responsible for enteric infections in HIV-positive patients is lacking [5].

Cryptosporidium, well known to veterinarians as a cause of diarrhoea in animals was first recognised as a cause of diarrhoea in man in 1976 [6]. Presently, Cryptosporidium is considered one of the most important opportunistic infective agents in patients with AIDS, in whom they are associated with protracted diarrhoea [7]. With the increasing number of individuals with HIV/AIDS, cancer patients and malnourished children suffering from diarrhoeal illness, need for an easy, cheap and quick method for diagnosis is required to reduce morbidity. Though ELISA has been widely used as a diagnostic tool, availability of this facility is still poor in peripheral set-up [8].

Non invasive diagnostic technique was first reported in 1978 by Pohlenz $\mathrm{J}$ et al for calves [9] and in 1980 by Tzipori S et al for humans [10], when oocyst were detected in faecal smears stained with Giemsa stain. Subsequently, numerous techniques to concentrate stool specimens and to stain oocysts have been applied for detection of Cryptosporium species. But there are little consensuses on which methods are most satisfactory. The present study was conducted to detect the presence of Cryptosporidium oocysts in the stool samples of HIVinfected patients. Kinyoun Cold Acid Fast (KCAF) technique and Auramine ' $\mathrm{O}$ ' Fluorochrome (AOF) staining techniques were employed in this study. The avenues of including ELISA in routine diagnostic use were also looked for.

\section{Materials and methods}

This prospective study was conducted over a period of one year, form July 2010 to June 2011, in the Department of Microbiology, Goa Medical College. Study group included all HIV seropositive individuals; they were further subdivided into two groups on the basis of presence of recurrent attacks of diarrhoea along with 
passage of blood and mucus, vomiting, abdominal pain and weight loss. The other group included those individuals having no gastrointestinal symptoms. The control group consisted of HIV seronegative individuals with or without diarrhoeal manifestations. A total of 120 randomly selected seropositive individuals (study group); along with $200 \mathrm{HIV}$ seronegative individuals (control group) were enrolled for this study as per the above criteria.

Subjects were adequately instructed regarding collection and submission of the stool specimen to the laboratory without undue delay. Microscopic examination of stool included normal saline and Lugol's iodine wet mounts. Diarrhoeal stool specimens usually contain enough oocysts to be readily identified despite fluctuations in the number of organisms and intermittent shedding [11, 12]. Hence, the usefulness of concentration methods for diagnosis of cryptosporidial infection is debatable. However, it would be useful in nonacute cases as an epidemiological marker. In the present study concentration method was not attempted since the main focus of the study was on prevalence of Cryptosporidium related diarrhoea in HIV infected individuals.

Air dried and methanol fixed smears were stained by KCAF and AOF staining methods [13], and was observed under $100 \mathrm{X}$ oil immersion objective and under 40X dry objective using U-V light respectively.

An aliquot each of all stool samples was kept at $4^{\circ} \mathrm{C}$ without any preservative and were subjected to ELISA test using Cryptosporidium microplate assay (alexon Inc.). This ELISA is used for qualitative detection of Cryptosporidium specific antigen in aqueous extracts of faecal specimens. The protocol was followed as per the manufacturer's instructions and test read spectrophotometrically.

\subsection{Statistical analysis:}

All tests performed for evidence of Cryptosporidium were compared and evaluated statistically using chi-square test as the criteria for significance of test values.

\section{Analysis of the results}

A total of 320 subjects included in this study, were divided into 4 groups based on HIV seropositivity or seronegativity and presence or absence of diarrhoea (Table 1). In the parasitological examination of stool sample, protozoan parasites accounted for $14.37 \%$ (46/320), whereas helminths were observed in $19.06 \%$ $(61 / 320)$ of all subjects studied. In the entire study population, the spore forming protozoan parasites encountered by any of the methods employed include Cryptosporidium (40/320; $12.5 \%)$, Isospora $(1 / 320$; $0.31 \%)$ and Microspora $(1 / 320 ; 0.31 \%)$. Special attention was however given to Cryptosporidium (Table 2).

Using KCAF staining method, Cryptosporidium oocysts were detected in 21 subjects of HIV positive groups $(21 / 120 ; 17.5 \%)$. Only 9 HIV seronegative subjects $(9 / 200 ; 4.5 \%)$ showed the presence of Cryptosporidium oocysts in their stools. This observed difference in isolation of Cryptosporidium oocysts in various groups of HIV seropositive and HIV seronegative individuals with or without diarrhoea using KCAF staining method, is highly significant $(\mathrm{p}<0.01)$ (Table 3 ).

Results of AOF staining on all stool samples show that Cryptosporidium oocysts were detected in $7.5 \%(9 / 120)$ of HIV seropositive and 2\% (4/200) of HIV seronegative individuals. The observed difference in isolation of Cryptosporidium oocysts using AOF staining in various study groups is not statistically significant (p>0.05) (Table 4). When comparing KCAF staining and AOF staining method it was observed that except for 2 specimens which were found positive for Cryptosporidium oocysts by AOF staining alone, other all samples were positive by both staining methods.

ELISA for coprodiagnosis of Cryptosporidium antigen, showed a positive result in 26/120 (21.67\%) HIV seropositive subjects. The difference in Cryptosporidium antigen isolation using ELISA test in stool samples of various study groups is statistically highly significant $p<0.01$ (Table 5).

Taking KCAF staining method as gold standard for the diagnosis of cryptosporidiosis, the results of AOF staining were correlated with it. Evaluating the efficacy of AOF staining with reference to KCAF staining method as a gold standard, using chi- square, the test results were found to be highly significant $(\mathrm{p}<0.001$ ) (Table 6).

Results of ELISA test for Cryptosporidium antigen detection when correlated with results of gold standard the $\mathrm{p}$ value $(<.001)$ suggests that the ELISA test result is significantly useful for predicting positive and negative results with reference to KCAF staining as the gold standard (Table 7).

Comparison of parameters for the three tests performed in this study reveals (Table 8) that AOF staining is the most specific test for the diagnosis of cryptosporidiosis, assuming KCAF staining as gold standard; ELISA test is most sensitive single test for detecting the infestation. A combination of AOF staining and ELISA test improves the sensitivity to $90 \%$ while retaining high specificity of around $97 \%$. 


\section{Discussion}

Cryptosporidium, an intestinal protozoan parasite, once known to be a causative agent of acute diarrhoea in animals [14], has now emerged as one of the main cause of prolonged and life threatening diarrhoea in immunocompromised patients and particularly so, in patients suffering from AIDS [15]. A number of workers have studied the possible association between this coccidian parasite and AIDS patients $[16,17,18,19$, $20]$.

In the present study, the overall prevalence of Cryptosporidium was found to be $12.5 \%$, the prevalence however was $25.8 \%$ in HIV positive subjects and still higher in HIV positive subjects suffering from diarrhoea (33.3\%). The possible role of Cryptosporidium causing diarrhoea in HIV seropositive patients may be attributable in some, to the enterocyte or neural dysfunction related to HIV infection [21,22]. Alternatively, there may be quantitative differences in parasite burden between patients with and without diarrhoea. In this study however, the oocysts detected were not quantified.

In present study population, $32.81 \%$ subjects had parasitic infestation, out of which $48.3 \%$ were found in HIV positive subjects with diarrhoea. Helminths formed the major parasites detected $(19.06 \%)$, Cryptosporidium species was the major protozoan in this category (86.95\%). A study conducted in normal healthy population in Goa, showed the overall prevalence of helminthic infestation to be $41 \%$ using concentration methods [23].A lower isolation of helminths in the present study could be attributed to the area to which our institution is catering. The area being urban, a better sanitary environment and a moderate personal hygiene could have contributed to a lower prevalence of parasite infestation. Secondly, the population coming to the hospital is not a true representation of general population as a whole. Non usage of concentration techniques could have also contributed to lower parasite detection. Among the protozoan, higher isolation rate of Cryptosporidium species could be due to special emphasis given to this parasite, or probably it was a true higher incidence, although further studies are required in this field to ascertain the prevalence of other coccidian parasites in the community.

Using KCAF staining procedure $20 \%$ of HIV infected subjects with diarrhoea in our study were identified as being infested with Cryptosporidium oocysts. In contrast only $7 \%$ of HIV negative individuals with diarrhoea had Cryptosporidium oocysts in their stool samples. Comparative studies rank KCAF staining method highest in terms of the reagent cost, hands-on time required, yield, ease of handling and ability to process large numbers of specimens, although there was some difficulty of interpretation at times [24, 25]. Keeping these points in mind and also that KCAF staining technique is the method of choice for the coprodiagnosis of Cryptosporidium oocysts in most of the microbiological laboratories [26], we selected KCAF staining method for identification of Cryptosporidium oocysts in stool samples of our subjects as well as the 'gold standard' for our study when comparing the other methods.

AOF staining method has been recommended as an alternative to KCAF staining [27]. In this study, using AOF staining Cryptosporidium species was detected in $4.06 \%$ of the whole study population. When compared to KCAF staining, AOF staining could detect Cryptosporidium oocysts in only 11 out of 30 stool samples which were positive for Cryptosporidium oocysts. However, 2 additional samples were found positive by this method. We found AOF staining to be a rapid diagnostic screening method. The Auramine ' $\mathrm{O}$ ' staining method may be particularly useful for screening larger number of faecal samples for Cryptosporidium oocysts. Few studies have assessed the usefulness of fluorescent staining statistically. A comparative study conducted by Arrowood MJ etal [28] observed Auramine -rhodamine fluorescent staining method to be $93.8 \%$ sensitive and $85.7 \%$ specific. Disadvantages of this technique include its complexity, which required frequent quality control monitoring, and technological expertise, and the fact that it is a nonspecific stain.

All stool samples were subjected to ELISA test using Prospect Cryptosporidium microplate assay (Alexon inc.) for detection of Cryptosporidium antigen. We documented the presence of Cryptosporidium antigen in $21.67 \%$ of HIV seropositive persons studied. 25 of 30 samples positive for Cryptosporidium by KCAF staining were also positive by ELISA. Additionally 10 samples were found positive by ELISA. The sensitivity and specificity were observed to be $83.33 \%$ and $96.55 \%$ respectively. These figures correlate closely with two other studies documented [29,30]. Possible reasons for microscopy negative, ELISA positive result of a specimen may be attributed to the fact that a fewer number of oocysts have to be present for their detection by microscopy. ELISA on the other hand detected even disintegrating organisms and their products [30].

\section{Conclusion}

Cryptosporidium parvum, a relatively obscure protozoan parasite has generated interest over the past few decades is now gaining the recognition it deserves as an important, widespread cause of diarrhoeal illness in humans. It is important that health care professionals emphasize the importance of Cryptosporidium in the differential diagnosis of diarrhoeal illness. This educational role should be approached aggressively because of the common occurrence of the infection, large number of potential reservoir hosts and persons with impaired immune function may develop life threatening cryptosporidiosis. 
At present microscopic examination by one or more staining technique remains the 'gold standard' for the diagnosis of cryptosporidiosis [29]. It is suggested to review the spectrum of methods for diagnosis of Cryptosporidium that are available, for a thorough review of 'gold standard' in today's context. As ELISA test is based on the detection of cryptosporidial antigen and is capable of detecting even disintegrated cells, the fulcrum for gold standard is tilting in its favour. Moreover, comparing with the microscopic techniques to diagnose infection, in terms of personnel time and economy, ELISA is quite practical. This assay also eliminates the need for skills in expertise involved in performing complicated staining procedures and recognizing morphology of oocysts of Cryptosporidium.

The technique to be adopted for screening Cryptosporidium oocysts will have to be decided with caution, considering cost constrains and availability, a selective approach might be more reasonable. Screening all patients with diarrhoea has been recommended.

Table 1

Details of subjects included in the study

\begin{tabular}{|l|l|l|}
\hline Study groups & Description & Number studied \\
\hline Group I & HIV positive with diarrhoea & 60 \\
\hline Group II & $\begin{array}{l}\text { HIV positive without } \\
\text { diarrhoea }\end{array}$ & 60 \\
\hline Group III & HIV negative with diarrhoea & 100 \\
\hline Group IV & $\begin{array}{l}\text { HIV negative without } \\
\text { diarrhoea }\end{array}$ & 100 \\
\hline Total & & $\mathbf{3 2 0}$ \\
\hline
\end{tabular}

Table 2

Parasites detected in faecal samples of all four study group individuals

\begin{tabular}{|c|c|c|c|c|}
\hline Parasites detected & $\begin{array}{l}\text { Group I } \\
\mathbf{n}=\mathbf{6 0}\end{array}$ & $\begin{array}{l}\text { Group II } \\
\mathbf{n}=60\end{array}$ & $\begin{array}{l}\text { Group III } \\
\mathbf{n}=100\end{array}$ & $\begin{array}{l}\text { Group IV } \\
n=100\end{array}$ \\
\hline $\begin{array}{l}\text { Protozoa } \\
\text { Cryptosporidium species } \\
\text { Microspora species } \\
\text { Isospora species } \\
\text { Entamoeba histolytica }\end{array}$ & $\begin{array}{l}20(33.3) \\
1(1.67) \\
- \\
-\end{array}$ & $\begin{array}{l}11(18.3) \\
- \\
- \\
-\end{array}$ & $\begin{array}{l}7(7) \\
- \\
1(1) \\
2(2)\end{array}$ & $\begin{array}{l}2(2) \\
- \\
- \\
2(2)\end{array}$ \\
\hline $\begin{array}{l}\text { Nematehelminth } \\
\text { Ascaris lumbricoides } \\
\text { Hookworm } \\
\text { Strongyloides stercoralis } \\
\text { Trichuris trichiura }\end{array}$ & $\begin{array}{l}5(8.3) \\
2(3.3) \\
1(1.67) \\
-\end{array}$ & $\begin{array}{l}2(3.3) \\
2(3.3) \\
- \\
-\end{array}$ & $\begin{array}{l}14(14) \\
7(7) \\
- \\
1(1)\end{array}$ & $\begin{array}{l}14(14) \\
9(9) \\
- \\
3(3)\end{array}$ \\
\hline $\begin{array}{l}\text { Platyhelminth } \\
\text { Taenia species } \\
\end{array}$ & - & - & $2(2)$ & - \\
\hline Total Number Isolated & $29(48.3)$ & 15(25) & 31(31) & 30(30) \\
\hline
\end{tabular}

Table 3

Detection of Cryptosporidium in stool sample by Kinyoun Cold Acid Fast staining method

\begin{tabular}{|c|c|c|c|c|}
\hline Result & $\begin{array}{l}\text { Group } \\
\text { I }\end{array}$ & Group II & $\begin{array}{l}\text { Group } \\
\text { III }\end{array}$ & $\begin{array}{l}\text { Group } \\
\text { IV }\end{array}$ \\
\hline Cryptosporidium Positive & $12(20)$ & $9(15)$ & $7(7)$ & $2(2)$ \\
\hline Cryptosporidium Negative & $48(80)$ & $51(85)$ & $93(93)$ & $98(98)$ \\
\hline Total & 60 & 60 & 100 & 100 \\
\hline
\end{tabular}

N.B. Figures in parentheses indicate percentage

chi-square : $\mathrm{p}<0.01$

Interpretation: Highly significant 
Table 4

Detection of Cryptosporidium in stool sample by Auramine ' $O$ ' fluorochrome staining method

\begin{tabular}{|l|l|l|l|l|}
\hline Result & Group I & Group II & $\begin{array}{l}\text { Group } \\
\text { III }\end{array}$ & $\begin{array}{l}\text { Group } \\
\text { IV }\end{array}$ \\
\hline Cryptosporidium Positive & $5(8.3)$ & $4(6.7)$ & $3(3)$ & $1(1)$ \\
\hline Cryptosporidium Negative & $55(91.7)$ & $56(93.3)$ & $97(97)$ & $99(99)$ \\
\hline Total & $\mathbf{6 0}$ & $\mathbf{6 0}$ & $\mathbf{1 0 0}$ & $\mathbf{1 0 0}$ \\
\hline
\end{tabular}

N.B. Figures in parentheses indicate percentage

chi-square $\quad: \mathrm{p}>0.05$

Interpretation : Not significant

Table 5

Detection of Cryptosporidium antigen in stool samples using ELISA test

\begin{tabular}{|l|l|l|l|l|}
\hline Result & Group I & Group II & $\begin{array}{l}\text { Group } \\
\text { III }\end{array}$ & $\begin{array}{l}\text { Group } \\
\text { IV }\end{array}$ \\
\hline Cryptosporidium Positive & $18(30)$ & $8(13.3)$ & $7(7)$ & 0 \\
\hline Cryptosporidium Negative & $42(70)$ & $52(86.7)$ & $93(93)$ & $100(100)$ \\
\hline Total & $\mathbf{6 0}$ & $\mathbf{6 0}$ & $\mathbf{1 0 0}$ & $\mathbf{1 0 0}$ \\
\hline
\end{tabular}

N.B. Figures in parentheses indicate percentage

chi-square: $\quad \mathrm{p}<0.01$

Interpretation: Highly significant

Table 6

Comparison of Auramine 'O' fluorochrome staining with Kinyoun Cold Acid Fast staining method

\begin{tabular}{|l|lr|l|l|}
\hline $\begin{array}{l}\text { Gold standard } \\
\text { Test }\end{array}$ & $\begin{array}{l}\text { Positive } \\
\text { Kinyoun } \\
\text { Acid } \\
\text { staining }\end{array}$ & $\begin{array}{r}\text { bogative by } \\
\text { Fast }\end{array}$ & $\begin{array}{l}\text { Total } \\
\text { Kinyoun Cold } \\
\text { Acid Fast } \\
\text { staining }\end{array}$ & \\
\hline $\begin{array}{l}\text { Positive by Auramine 'O' } \\
\text { staining }\end{array}$ & 11 & 2 & 13 \\
\hline $\begin{array}{l}\text { Negative by Auramine 'O' } \\
\text { staining }\end{array}$ & 19 & 288 & 307 \\
\hline Total & $\mathbf{3 0}$ & $\mathbf{2 9 0}$ & $\mathbf{3 2 0}$ \\
\hline
\end{tabular}

Sensitivity

Specificity

$$
\begin{gathered}
=36.67 \% \\
=99.31 \% \\
85 \% \\
=94 \%
\end{gathered}
$$

Positive Predictive Value

Negative Predictive Value

chi-square:

$=85 \%$

Interpretation:

$$
\begin{aligned}
& \mathrm{p}<0.001 \\
& \text { Highly significant }
\end{aligned}
$$

\begin{tabular}{|c|c|c|c|}
\hline 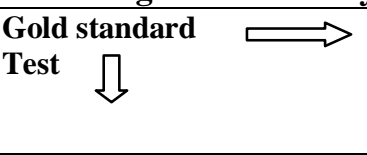 & $\begin{array}{lr}\text { Positive } & \text { by } \\
\text { Kinyoun } & \text { Cold } \\
\text { Acid } & \text { Fast } \\
\text { staining } & \end{array}$ & $\begin{array}{lr}\text { Negative } & \text { by } \\
\text { Kinyoun } & \text { Cold } \\
\text { Acid } & \text { Fast } \\
\text { staining } & \end{array}$ & Total \\
\hline $\begin{array}{l}\text { ELISA Positive for } \\
\text { Cryptosporidium antigen }\end{array}$ & 25 & 10 & 35 \\
\hline $\begin{array}{l}\text { ELISA Negative for } \\
\text { Cryptosporidium antigen }\end{array}$ & 5 & 280 & 285 \\
\hline Total & 30 & 290 & 320 \\
\hline
\end{tabular}

Table 7

Comparison of Antigen detection by ELISA with Kinyoun Cold Acid Fast staining method

Sensitivity

Specificity

$$
=83.33 \%
$$

Positive Predictive Value $=71 \%$

Negative Predictive Value $=98 \%$

chi-square:

$\mathrm{p}<0.001$

Interpretation:

Highly significant 
Table 8

Comparison of parameters for different tests

\begin{tabular}{|l|l|l|}
\hline $\begin{array}{l}\text { Tests } \\
\text { Parameters }\end{array}$ & $\begin{array}{l}\text { Auramine 'O' fluorochrome } \\
\text { staining }\end{array}$ & $\begin{array}{l}\text { ELISA } \\
\text { Cryptosporidium antigen } \\
\text { detection }\end{array}$ \\
\hline Sensitivity (\%) & 36.67 & 83.33 \\
\hline Specificity (\%) & 99.31 & 96.55 \\
\hline Positive Predictive Value (PPV) (\%) & 85 & 71 \\
\hline $\begin{array}{l}\text { Negative Predictive Value (NPV) } \\
(\%)\end{array}$ & 94 & 98 \\
\hline chi-square value & $<0.001$ & $<0.001$ \\
\hline
\end{tabular}

\section{References}

[1] Mirdha BR, Banerjee U, Sethi S, Samantaray JC, Malaviya AN. Spectrum of opportunistic fungal and parasitic infection in hospitalized AIDS patients. CARC calling 1993; Vol.6 No.2 Apr-June: 9-10.

[2] DR Arora, B Arora AIDS associated parasitic diarrhoea. IJMM.2009; 27(3): 185-190.

[3] Lew EA, Poles MA, Dieterich DT. Diarrhoeal diseases associated with HIV infection. Gastroenterol. Clin. North. Am. 1997; 26:259-90.

[4] Lubeck DP, Benneth CL, Mazonsen PD, Fifer SK, Fries JF. Quality of life and health service use among HIV-infected patients with chronic diarrhoea. J. Acquir. Immune. Defic. Syndr. 1993; 6: 478-84.

[5] Prasad K.N., Nag V.L., Dhole T.N., Ayyagari A. Identification of Enteric Pathogens in HIV- positive Patients with Diarrhoea in Northern India. J HEALTH POPUL NUTR 2000; Jun;18(1):23-26

[6] Casemore DP, Sands RL, Curry A. Cryptosporidium species a "new" human pathogen. J. Clin. Pathol. 1985; 38:1321-1336.

[7] Bonilla LC, De Young MM, Canor G, Jesus E, Bonilla E. Cryptosporidium infections in a Suburban community in Maracaibo; Venezuela. Am. J. Trop. Med. Hyg. 1993; 49(1):63-67.

[8] Barua P, Hazarika N K, Barua N, Rasul E, Laskar N. Microscopy for cryptosporidiosis screening in remote areas. Indian J Med Microbiol [serial online] 2008 [cited 2013 Mar 8]; 26: 203-4. Available from: http://www.ijmm.org/text.asp?2008/26/2/203/40550

[9] Pohlenz J, Moon HW, Cheville NF, Bemrick WJ. Cryptosporidiosis as a probable factor in neonatal diarrhoea of calves. J. Am. Vet. Med. Assoc. 1978; 172: 452-7

[10] Tzipori S, Angus KW, Campbell I, Grey EW. Cryptosporidium: evidence of a single species genus. Infect. Immun. 1980;30: 884-6

[11] Garcia LS, Bruckner DA, Brewer TC, Shimizu RY. Techniques for the recovery and identification of Cryptosporidium oocysts from stool specimens. J. Clin. Microbiol.1983; 18: 185-190.

[12] Weber J, Philip S. Human Cryptosporidium. N. Eng. J. Med. 1983; 309:1326.

[13] Washington W J, AllenS, Janda W, Koneman E, Procop G, Schreckenberger P, Woods G. Koneman's color atlas and textbook of microbiology $6^{\text {th }}$ edition. Lippincott Williams and Wilkins, 2006;26, 1076

[14] Navin TR Juranek DD. Cryptosporidiosis: Chemical epidemiologic and parasitologic review. Rev. Infect. Dis.1984; 6: 313-27.

[15] Gellin BG, Soave R. Coccidian infection in AIDS. Med. Clinc. N. Am.1992; 76; 1: 205-234.

[16] Ajjampur Rao SS, Asirvatham JR, Muthusamy D, Gladstone BP, Abraham OC, Mathai D, Ward H, Wanke C, Kang G. Clinical features \& risk factors associated with cryptosporidiosis in HIV infected adults in India. Indian J Med Res. 2007 December; 126(6): 553-557.

[17] Jha AK, Uppal B, Chadha S, Bhalla P, Ghosh R, Aggarwal P, Dewan R. Clinical and Microbiological Profile of HIV/AIDS Cases with Diarrhea in North India. Journal of Pathogens Volume 2012, Article ID 971958, 7 pagesdoi:10.1155/2012/971958.

[18] Kulkarni SV, Kairon R, Sane SS, Padmawar PS, Kale VA, Thakar MR, Mehendale SM, Risbud AR. Opportunistic parasitic infections in HIV/AIDS patients presenting with diarrhoea by the level of immune suppression. Indian J Med Res 130, July 2009; pp 63-66

[19] Ajjampur SS, Sankaran P, Kang G. Cryptosporidium species in HIV-infected individuals in India: an overview. Natl. Med. J. India. 2008 Jul-Aug; 21(4):178-84.

[20] Hunter PR, Nichols G. Epidemiology and Clinical Features of Cryptosporidium Infection in Immunocompromised Patients. CMR . Jan 2002;15 (1):145-154

[21] Batman PA, Miller AR, Sedgwick PM, Griffin GE. Automatic denervation in jejuna mucosa of homosexual men infected with HIV. AIDS 1991;5: 1247-52

[22] Bartlett JG, Belitsos PC, Sears CL. AIDS enteropathy. Clin. Infect. Dis. 1992; 15:726-35

[23] Estibeiro S, Pinto MJW, Rodrigues S, Verenkar MP. Prevalence of Taenia infestation in 3 areas of Goa. Ind.J.Med. Micro. 2000; $18(3) ; 116-118$.

[24] Mac Pherson DW, Mc Queen R. Cryptosporidiosis: Multiattribute evaluation of six diagnostic methods. J. Clin. Microbiol. 1993;31:2:198-202

[25] Kehl KSC, Cicirello H, Havens PL. Comparision of four different methods for detection of Cryptosporidium species. J. Clin. Microbilo. 1995; 33; 2:416-418

[26] Henricksen SA,Pohlenz JFL. Staining of Cryptosporidia by modified Ziehl -Neelsen technique. Acta. Vet. Scand. 1981; 22: 594-6

[27] Thom BT, Nichols G. Screening for Cryptosporidium in stools. Lancet. 1984; I: 735

[28] Arrowood MJ, Hurd MR, Mead JR. A new method for evaluating experimental cryptosporidial parasite loads using immunofluorescent flow cytometry. J. Parasitol. 1995; 81: 404-409

[29] Newman RD, Wuhib T, Lima AA, Guerrnat RL, Sears CL. Environmental sources of Cryptosporidium in an urban slum in northeastern Brazil. Am. J. Trop. Med. Hyg. 1993; 49(2): 270-275.

[30] Ungar BPL. Enzyme-linked Immune assay for detection of cryptosporidium antigen in fecal specimens. J. Clin. Microbiol. 1990, 28;11: 2491-2495 